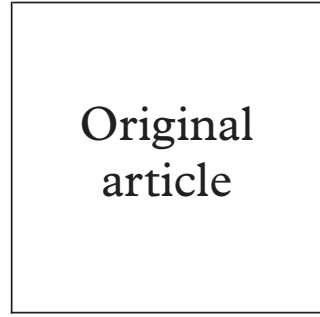

\section{Department of Gynecology, UNICAMP, Campinas, Brazil \\ S F M Derchain \\ C M Roteli-Martins}

Leonor Mendes de

Barros Hospital, São

Paulo, Brazil

C M Roteli-Martins

Department of Pathology, University of Siena, Siena, Italy K J Syrjänen

Department of Medical Statistics, UNICAMP, Campinas, Brazil

H J de Abreu

E Z Martinez

\section{Department of}

Pathology, USP-São

Paulo, Brazil

V A F Alves

Correspondence to: Dr Sophie F M Derchain, Rua Antônio Hossri, 629, Cidade Universitária, CEP 13083-140, Campinas, SP, Brazil

Accepted for publication 26 August 1999

\title{
Association of oncogenic human papillomavirus DNA with high grade cervical intraepithelial neoplasia: the role of cigarette smoking
}

Sophie Françoise Mauricette Derchain, Cecilia Maria Roteli-Martins, Kari Juhani Syrjänen, Helio José de Abreu, Edson Zangiacomi Martinez, Venancio Avancini Ferreira Alves

\section{Introduction}

Human papillomavirus (HPV) is currently considered as the main aetiological factor of cervical cancer and its precursor cervical intraepithelial neoplasia (CIN). ${ }^{1}$ The integration of HPV DNA in the human genome is crucial for persistence of the virus and its carcinogenic effects. Molecular mechanisms and cellular events associated with viral persistence are still poorly understood, although it seems likely that a permissive viral replication increases the viral load in infected cells. Correlation between the viral load and persistence of the infection is indirect; in women with HPV induced cytopathic changes, a high load of oncogenic HPV types is strongly associated with CIN 2 and CIN 3. ${ }^{2}$ The role of smoking as a risk factor for CIN and cervical cancer has been repeatedly emphasised starting from the late 1980 s, although the results still remain controversial. ${ }^{3-8}$ This study was designed to evaluate the independent role of current smoking and viral load of the oncogenic (high risk) HPV types as predisposing factors for CIN 2 and CIN 3.

\section{Material and methods}

The subjects of this study were selected among 163 women referred to the colposcopy clinics of Leonor Mendes de Barros and CAISM/ UNICAMP hospitals, between September 1995 and August 1997 because of HPV suggestive abnormalities in their Papanicolaou smears. The protocol was approved by the institutional review board, and all women gave informed consent. The patients filled in a detailed questionnaire requesting their social, sexual, and reproductive histories.

A total of 148 women aged between 18 and 36 years (mean 27 years), who presented with an abnormal pattern on colposcopy warranting a directed punch biopsy, were included. Histological changes were evaluated according to the WHO classification ${ }^{9}$ into the following categories: absence of HPV lesion, CIN 1, CIN 2, or CIN 3. On light microscopy, 42 women showed no HPV lesion on the cervix, 69 had CIN 1, 24 showed a CIN 2, and 13 showed CIN 3.

For the HPV DNA analysis, the first generation hybrid capture (HC) HPV DNA assay, including high risk HPV probes for types $16,18,31,33,35,45,51,52$, and 56 was used according to the instructions of the manufacturer (Digene, USA). A cut off level of 1 relative light unit (RLU) was used, signifying that the samples with light emission higher than 1 RLU are considered HPV positive. Based in the data of Wright et $a l^{10}$ the viral load was classified as low when ranging from 1 to 5 RLU, intermediate when ranging from 5.1 to $20 \mathrm{RLU}$, and high when above 20 RLU. HC, colposcopy, and directed biopsy were collected with a median interval of 13 weeks (minimal of 4 and maximal 21 weeks) after the Pap smears.

The distribution of the risk factors was compared among women with no HPV lesion and CIN by univariate logistic regression, and the odds ratio was calculated with a confidence interval of $95 \%$. After this, a polytomous logistic regression analysis model was used to check the independent associations between the studied variables and CIN. Because CIN 2 and 3 are considered high grade lesions they were analysed together. By choosing the women with no HPV lesions as the base category for the dependent variable, the model estimated two risk equations simultaneously: (a) the odds for having CIN $1 v$ no HPV lesion and (b) the odds for having CIN 2 and $3 v$ no HPV lesion. In all data analysis, EPI-INFO 6.02 and SAS (Statistical Analysis System) were used.

\section{Results}

The overall detection rate of HPV DNA was $48 \%$ (71/148 women) and the detection rate increased significantly with the grade of CIN. The probability of CIN 2 and CIN 3 was also directly related to the viral load. Accordingly, odds ratio (OR) for CIN 2 or 3 was 14.57 in women with low viral load, reaching the value of 20.64 in those with a high viral load, compared with the women with a negative HC test (table 1).

An early onset of sexual activity, cigarette smoking, and the presence of HPV DNA were factors associated with CIN 2 or 3 in the polytomous logistic regression analysis (table 2). Women who smoke presented with an adjusted OR of 4.37 for having developed CIN 2 or 3 compared with the non-smokers. Women with positive HC test for the oncogenic HPV DNA had an adjusted OR 14.40 of presenting CIN 2 or 3 compared with those who tested as HPV negative. 
Table 1 Lifestyle variables and HPV status of the cervical lesions in univariate regression analysis

\begin{tabular}{|c|c|c|c|c|c|c|c|}
\hline & \multicolumn{3}{|l|}{ Histological diagnosis } & \multicolumn{2}{|c|}{ Without HPV lesion v CIN 1} & \multicolumn{2}{|c|}{ Without HPV lesion $v$ CIN 2 and 3} \\
\hline & $\begin{array}{l}\text { Without HPV lesion } \\
\text { No }(\%)\end{array}$ & $\begin{array}{l}\text { CIN } 1 \\
\text { No (\%) }\end{array}$ & $\begin{array}{l}\text { CIN } 2 \text { or } 3 \\
\text { No (\%) }\end{array}$ & Crude OR & $(95 \% C I)$ & Crude OR & $(95 \% C I)$ \\
\hline \multicolumn{8}{|l|}{ Race } \\
\hline White & $30(71)$ & $53(77)$ & $28(76)$ & 1.0 & & 1.0 & \\
\hline Non-white & $12(29)$ & $16(23)$ & $9(24)$ & 0.76 & $(0.32 ; 1.81)$ & 0.86 & $(0.29 ; 2.20)$ \\
\hline \multicolumn{8}{|l|}{ Schooling } \\
\hline$>4$ years & $9(21)$ & $20(29)$ & $15(41)$ & 1.0 & & 1.0 & \\
\hline$<4$ years & $33(71)$ & $49(71)$ & $22(59)$ & 0.67 & $(0.27 ; 1.65)$ & 0.40 & $(0.15 ; 1.07)$ \\
\hline \multicolumn{8}{|c|}{ Lifetime number of sexual partners } \\
\hline One & $23(55)$ & $23(33)$ & $17(46)$ & 1.0 & & 1.0 & \\
\hline More than one & $19(45)$ & $46(67)$ & $20(54)$ & 2.42 & $(1.10 ; 5.32)$ & 1.18 & $(0.49 ; 2.80)$ \\
\hline \multicolumn{8}{|c|}{ Age at first sexual intercourse } \\
\hline$>18$ years & $23(55)$ & $33(48)$ & $8(22)$ & 1.0 & & 1.0 & \\
\hline$<18$ years & $19(45)$ & $36(52)$ & $29(78)$ & 1.32 & $(0.61 ; 2.85)$ & 4.39 & $(1.63 ; 11.82)$ \\
\hline \multicolumn{8}{|l|}{ Parity } \\
\hline Nulliparous & $9(21)$ & $15(30)$ & $3(8)$ & 1.0 & & 1.0 & \\
\hline One childbirth or more & $33(79)$ & $35(70)$ & $34(92)$ & 0.64 & $(0.25 ; 1.65)$ & 3.09 & $(0.77 ; 12.43)$ \\
\hline \multicolumn{8}{|l|}{ Current smoker } \\
\hline No & $30(71)$ & $44(64)$ & $11(30)$ & 1.0 & & 1.0 & \\
\hline Yes & $12(29)$ & $25(36)$ & $26(70)$ & 1.42 & $(0.62 ; 3.26)$ & 5.91 & $(2.24 ; 15.62)$ \\
\hline \multicolumn{8}{|l|}{ High risk HPV DNA } \\
\hline Absent & $34(81)$ & $36(49)$ & $7(19)$ & 1.0 & & 1.0 & \\
\hline Present & $8(19)$ & $37(51)$ & $30(81)$ & 4.37 & $(1.78 ; 0.71)$ & 18.21 & $(5.90 ; 56.12)$ \\
\hline \multicolumn{8}{|c|}{ Viral load in HPV DNA positive women } \\
\hline HPV negative & $34(80)$ & $36(52)$ & $7(19)$ & 1.0 & & 1.0 & \\
\hline Low (1-5 RLU) & $2(5)$ & $9(13)$ & $6(16)$ & 4.25 & $(0.86 ; 21.10)$ & 14.57 & $(2.42 ; 87.32)$ \\
\hline Median (5.1-20 RLU) & $2(5)$ & $8(12)$ & $7(19)$ & 3.78 & $(0.75 ; 19.07)$ & 17.00 & $(2.90 ; 99.76)$ \\
\hline High (>20 RLU) & $4(10)$ & $16(23)$ & $17(46)$ & 3.78 & $(1.15 ; 12.44)$ & 20.64 & $(5.30 ; 80.39)$ \\
\hline
\end{tabular}

\section{Discussion}

Among the 148 young Brazilian women analysed in the present study, the association of current smoking with the severity of CIN was evident and remained as an independent risk factor, significantly associated with CIN 2 and 3 in the multivariate analysis as well. The results are in alignment with other recent studies. Thus, Olsen et al established an intimate interrelation between smoking, high risk HPV type 16, and CIN 2/3: the OR for CIN 2 and 3 in HPV type 16 positive smokers and nonsmokers was 65.9 and 15.7 , respectively. ${ }^{8}$ The same was true with the detection of high risk HPV DNA in these women, which is in alignment with the data of Kanetsky et al who also demonstrated an association between cigarette smoking and cervical dysplasia in nonHispanic black women, after adjustment for $\mathrm{HPV}$ infection (HC assay). ${ }^{6}$

Recently, the viral load has been associated with CIN in cross sectional studies. In our series, the adjusted OR of presenting with CIN 2 or CIN 3 was 14.40 times higher in women with positive HC test (for oncogenic types), and the viral load was directly related to the grade of CIN. However, to more accurately

Table 2 Factors significantly associated with CIN 2 and 3 in the polytomous logistic regression analysis

\begin{tabular}{|c|c|c|c|c|c|c|}
\hline & \multicolumn{3}{|c|}{ CIN 1 v without HPV lesion } & \multicolumn{3}{|c|}{ CIN 2 and 3 without HPV lesion } \\
\hline & $\begin{array}{l}\text { Adjusted } \\
\text { OR }\end{array}$ & $(95 \% C I)$ & $p$ Value & $\begin{array}{l}\text { Adjusted } \\
\text { OR }\end{array}$ & $(95 \% C I)$ & $p$ Value \\
\hline \multicolumn{7}{|c|}{ Current smoker } \\
\hline No & 1.0 & & & 1.0 & & \\
\hline Yes & 1.25 & $(0.52 ; 2.96)$ & 0.62 & 4.37 & $(1.48 ; 12.92)$ & $<0.01$ \\
\hline \multicolumn{7}{|c|}{ Age at first sexual intercourse } \\
\hline$\geqslant 18$ years & 1.0 & & & 1.0 & & \\
\hline$<18$ years & 1.17 & $(0.52 ; 2.6)$ & 0.71 & 3.22 & $(1.05 ; 9.83)$ & 0.04 \\
\hline \multicolumn{7}{|c|}{ High risk HPV DNA } \\
\hline Absent & 1.0 & & & 1.0 & & \\
\hline Present & 3.76 & $(1.51 ; 9.34)$ & $<0.01$ & 14.40 & $(4.47 ; 46.40)$ & $<0.01$ \\
\hline
\end{tabular}

The likelihood ratio statistic has a value of 11.70 with eight degrees of freedom, which is indicative of a good fit $(\mathrm{p}=0.17)$, adjusted by race, schooling, lifetime number of sexual partners, and parity. predict the prognostic value of the viral load, it would be important to specifically assess the role of individual HPV types, and not merely examine the load of the virus pool included in the $\mathrm{HC}$ test.

Of the other risk factors established in the present series, the onset of sexual activity before the age of 18 contracted an adjusted OR of 3.22 for CIN 2/3. An early age at the first intercourse predisposes the woman to any sexually transmitted agents (such as HPV). The same effect is exerted by the number of lifetime sexual partners, established as a risk factor for CIN $2 / 3$ in a number of epidemiological studies. ${ }^{911}$

Although subjected to the potential temporal biases of a cross sectional study, the present series clearly demonstrates that the severity of the cervical precancer lesions is closely associated with (1) the presence of oncogenic HPV DNA, (2) cigarette smoking, and (3) early onset of sexual activity. The increase of the viral load was directly related to CIN $2 / 3$. Taken together with the current data on the causal role of HPV in cervical carcinogenesis, the present results imply that smoking and HPV might act synergistically in this process. ${ }^{3-8}$ To further elucidate the mechanisms of these suspected synergistic actions between HPV and cigarette smoke, however, additional experimental studies are necessary.

This study has been supported by a research grant from the research support fund of the state of São Paulo, FAPESP (gran number $96 / 1730-5$ )

Contributors: SFM Derchain had the initial idea for this project focused on analysing the interrelations of smoking and HPV in the development of CIN; CM Roteli-Martins, examined all patients and collected the data. Together, these two authors also wrote the project plan and the first version of this manuscript. KJ Syriänen has given constructive advice concerning the project design, as well as the composition of the manuin the pronuscript, including the discusson of statistical tests, and revising the English language of the paper a well as making suggestions to pertinent references. HJ de Abreu and EZ Martinez participated in the design of the study and they also made the statistical analysis. VAF Alves suggested the use of hybrid capture, and also read and classified all the cervical biopsies. 
1 Ho GYF, Bierman R, Beardsley L, et al. Natural history of cervicovaginal papillomavirus infection in young women. $N$ Engl f Med 1998;333:423-8.

2 Woodman CBJ, Rollason T, Ellis J, et al. Human papillomavirus infection and high risk of progression of epithelia abnormalities of the cervix. Br f Cancer 1996;73:553-6.

3 Burger MPM, Hollema H, Gouw ASH, et al. Cigarette smoking and human papillomavirus in patients with reported cervical cytological abnormality. BMF 1993;306:749-52.

4 Feldman JG, Chirgwin K, Dehovitz JÁ, et al. The association of smoking and risk of condyloma acuminatum in women. Obstet Gynecol 1997;89:346-50.

5 Ho GYF, Kadish AS, Burk RD, et al. HPV 16 and cigarette smoking as risk factors for high-grade cervical intrasmoking as risk factors for high-grade cerv

6 Kanetsky PA, Gammon MD, Mandelblatt J, et al. Cigarette smoking and cervical dysplasia among non-Hispanic black smoking and cervical dysplasia among
7 Nakao Y, Yang X, Yokoyama $\mathrm{M}$, et al. Malignant transformation of ectocervical cells immortalized by HPV 18: in vitro model of carcinogenesis by cigarette smoke. Carcinogenesis 1996; 17:577-83.

8 Olsen AO, Dillner J, Skrondal A, et al. Combined effect of smoking and human papillomavirus type 16 infection in cervical carcinogenesis. Epidemiology 1998;9:346-9.

9 Scully RE, Bonfiglio TA, Kurman RJ, et al. Histological typing of female genital tract tumors. International histological classification of tumours. 2nd ed. World Health Organisation. Berlin: Springler-Verlag, 1994.

10 Wright TC, Sun XW, Koulos J. Comparision of management algorithms for the evaluation of women with mew-grade cytologic abnormalities. Obstet Gynecol 1995;85. 202-10.

11 Kataja V, Syrjänen S, Yliskoski M, et al. Risk factors associated with cervical human papillomavirus infections: a casecontrol study. Am f Epidemiol 1993;138:735-45.9-19.

\section{Development of further national guidelines}

Following the publication of national management guidelines on 22 conditions as a supplement to the August edition of the journal Sexually Transmitted Infections, the Clinical Effectiveness Group of the MSSVD and AGUM is seeking the opinion of the wider specialty as to whether there is a need to develop guidelines on additional topics.

If you have any suggestions for future guideline development, please contact: Dr Keith Radcliffe, Chairman CEG, Consultant in GU Medicine, Whittall Street Clinic, Whittall Street, Birmingham B4 6DH; fax: 0121237 5729; email: k.w.radcliffe@bham.ac.uk 